\title{
Evidence for a link between IGF-I and cancer
}

\author{
Paul J Jenkins and Stephen A Bustin ${ }^{1}$ \\ Department of Endocrinology, St Bartholomew's Hospital, London EC1A 7BE, UK and ${ }^{1}$ Academic Department of Surgery, The Royal London Hospital, \\ London, UK \\ (Correspondence should be addressed to P J Jenkins; Email: P.J.Jenkins@qmul.ac.uk)
}

\begin{abstract}
Cancer risk is determined by a combination of environmental factors and genetic predisposition. Recent evidence suggests that dietary and related factors such as physical activity and body size may influence cancer risk through their effects on the serum concentration of IGF-I and its binding proteins. The growth hormone (GH)/IGF-I axis is involved in both human development as well as the maintenance of normal function and homeostasis in most cells of the body. In addition to their classical role as endocrine hormones, its members regulate a wide range of biological functions such as cell proliferation, differentiation and apoptosis through paracrine and autocrine mechanisms. During cancer development this complex network regulating tissue homeostasis breaks down, with inappropriate expression of the GH/IGF-I axis making an important contribution. The increased understanding of the molecular mechanisms and signalling pathways regulated by the GH/IGF-I axis has started to provide significant insights into the aetiology, prevention and therapy for a number of common cancers.
\end{abstract}

European Journal of Endocrinology 151 S17-S22

\section{Introduction}

The risk of developing cancer is determined by a combination of genetic factors and environmental effects, in particular diet and lifestyle. There is increasing evidence that the growth hormone $(\mathrm{GH}) /$ insulin-like growth factor (IGF)-I axis might provide a major link between these factors and the development of cancers through its influence on the regulation of normal cell proliferation, differentiation and apoptosis. Its inappropriate expression appears to contribute to the growth, maintenance and progression of the most common cancers, including cancers of the breast, lung and colon. It is also becoming clear that there are extensive interactions between the IGF-I, epidermal growth factor (EGF), oestrogen and insulin signal transduction pathways which provide further potential mechanisms through which the GH/IGF-I axis can influence cancer.

\section{Evidence implicating IGF-I in cancer}

Evidence linking IGF-I to the development and behaviour of malignant disease comes from a number of sources. Indirect evidence comes from clinical observations more than 50 years ago that women with breast cancer who had undergone hypophysectomy had an improved prognosis, an effect that was still apparent in those rendered oestrogen deficient by prior oophrectomy. More direct evidence is suggested by several prospective health screens indicating that individuals with higher serum IGF-I and lower IGF-binding protein (IGFBP)-3 levels within the normal range have an increased risk of many of the most common cancers, such as colon, breast, lung and prostate $(1-4)$. However, not all studies show this association, with one study reporting increased levels of IGFBP-3 (and IGFBP-2) in patients with colorectal cancer (5). Certainly, causality has not yet been established and elevated serum IGF-I levels in cancer patients may simply be a surrogate measure of some other process. For example, it remains to be explained why expression levels of IGFBP-3 and IGF-I, which are normally regulated by $\mathrm{GH}$ and strongly and directly correlated, become decoupled so that despite increased GH and IGF-I levels, IGFBP-3 serum levels are negatively correlated with colorectal cancer risk.

A positive influence of IGF-I in cancer development is further supported by the considerable evidence that patients with acromegaly are at an increased risk of cancer, especially colorectal (6). These reports also indicate that not only do colonic adenomas occur more frequently in these patients but they behave more aggressively with an increased tendency for malignant progression. Importantly, a prospective study involving a second colonoscopic evaluation, at intervals after the original screening examination when all visible polyps had been removed, revealed the occurrence of new adenomas to be significantly related to both serum $\mathrm{GH}$ and IGF-I levels (7). Previous work has also demonstrated the colonic epithelium of acromegalic patients to be characterised by increased proliferation which is proportional to serum IGF-I levels (8). This hyperproliferative state is in keeping with the known mitogenic and anti-apoptotic effects of IGF-I and suggests that the 
main tumorigenic effect of this growth factor is as a tumour promotor rather than carcinogenic initiator. The phenotypic characteristics of colorectal neoplasia in patients with acromegaly support this concept, in that the tumours tend to be on the right side of the colon, and are larger and more dysplastic than sporadic disease. The postulated carcinogen in this case is intralumenal bile acids which have undergone bacterial deconjugation in the right colon. These compounds, such as deoxycholic acid (DCA), have been strongly implicated in the development of sporadic colonic cancer and are increased in patients with acromegaly due in part to the prolonged colonic transit occurring in this condition (9). Thus, the increased IGF-I levels in acromegaly would increase the chances of survival of cells with damaged DNA in response to the elevated DCA levels, rather than the cells undergoing the normal protective apoptotic response.

\section{Endocrine vs local IGF-I}

It remains uncertain as to whether this important influence of the GH/IGF-I axis in cancer development and behaviour reflects its endocrine actions or whether paracrine/autocrine expression is also important. This is particularly pertinent in reference to recent work questioning the classical endocrine actions of the GH/IGF-I axis and the increasing appreciation that autocrine and paracrine actions of IGF-I are important for normal growth and development (10). These local effects have also recently been demonstrated to be important in colorectal tumorigenesis and tumour neovascularisation (11). Furthermore, the regulation of the GH/IGF-I axis in different tissues remains largely unexplored, both in terms of the regulation of GH and IGF-I expression themselves, but also with respect to the role of the various IGFBPs and proteases, as well as the intracellular signalling pathways involved in transducing its numerous effects. An indication that local IGF-I expression might contribute to circulating IGF-I levels in a pituitary $\mathrm{GH}$-independent manner is indicated by clinical observations that patients who have undergone total hypophysectomy and thus rendered completely $\mathrm{GH}$ deficient have serum IGF-I levels that are usually either within the normal range or just below it.

\section{IGF-I and IGF-I receptor (IGF-IR)}

The functions of IGF-I as a mitogen and anti-apoptotic survival factor are well documented. The single-copy IGF-I gene consists of six exons and is transcribed from two promoters located $5^{\prime}$ to exons 1 and 2 respectively. As with the GH receptor, alternative RNA splicing and differential polyadenylation results in considerable heterogeneity in mature IGF-I transcripts. Most studies have reported the presence of IGF-I mRNA in normal and malignant tissue, although a recent report detects its mRNA in only $60 \%$ of normal and $54 \%$ of colonic tumour biopsies (11). In addition to $\mathrm{GH}$, genetic predisposition plays an important role in determining circulating IGF-I levels (12), although the relative importance of genetic and environmental factors in intra- and inter-individual variation in IGF-I signalling remains to be determined. Although low serum IGF-I levels are associated with a polymorphic CA microsatellite within the IGF-I gene, its relevance to cancer risk is uncertain (13). Polymorphisms have also been reported within the IGFBP-3, insulin receptor substrate-1 (IRS-1) and $\mathrm{p} 85 \alpha$ subunit of phosphatidylinositol-3 kinase (PI-3K) genes and may alter the function of the relevant proteins.

The IGF-IR, together with the insulin receptor (IR) with which it shares $70 \%$ homology, comprises the type II receptor tyrosine kinase family and mediates most of the actions of both IGF-I and IGF-II. Expression from the IGF-IR promoter is downregulated by the Wilms' tumour suppressor protein (WT1) (14) and by wild-type p53, in contrast to mutant p53 which stimulates its activity without binding to its promoter (15). Physical interaction of p53 and WT1 stabilises p53 and inhibits its ability to induce apoptosis. Conversely, the transcriptional activity of WT1 proteins depends on the cellular status of p53 and in the presence of mutant p53 WT1 cannot suppress IGF-IR activity (16). The importance of the interaction of these two proteins is illustrated by the finding that in breast cancers WT1 and mutant p53 are co-expressed in more aggressive, oestrogen receptor (ER)-negative cancers (17). A recent report suggests universal upregulation of non-mutated WT1 in colorectal cancers (18), although a previous report did not show this (19). Therefore, the upregulation of IGF-IR in colorectal cancers could be a consequence of a possible sequestration of WT1 by mutant p53.

\section{Downstream effects of IGF-IR activation}

IGF-IR activation by ligand binding causes rapid tyrosine phosphorylation of IRS-1 and -2 and intracytoplasmic assembly of a complex consisting of a variety of proteins that are responsible for stimulating diverse downstream signal transduction pathways. The two main signalling pathways involve the PI-3K and the p21 ras/mitogen-activated protein kinase (MAPK) pathways. Docking of the adaptor protein SHC and Grb-2 links it to the Ras-Raf MAPK pathway and is often associated with proliferation. Interaction with the p85 subunit of the PI-3K couples it to the S6 kinase cascade, which frequently results in anti-apoptotic signalling. However, pathways are cell-type dependent and a strict separation of pathways is not possible as they will interact with and may even be able to replace each other. Choice of signalling pathway is also stimulus dependent: IGF-I can protect colon cancer cells from 
tumour necrosis factor- $\alpha$ (TNF- $\alpha$ )-induced apoptosis by potentiating the MAPK and nerve factor- $\kappa \mathrm{B}$ signalling pathways induced by TNF- $\alpha$ itself, even in the absence of cell adhesion-mediated signalling (20). One important element in the crosstalk between the two pathways may be Ras, which appears to have a dual function, since it is also an upstream effector of PI-3K. Furthermore, novel signalling pathways are constantly being identified, e.g. an IGF-IR-mediated survival signalling pathway that is independent of $\mathrm{PI}-3 \mathrm{~K}$ and protein kinase B (PKB)/Akt activity (21) and there is some suggestion that tumour cells can employ different pathways from those described in non-transformed cells (22).

\section{Signalling specificity}

The specific signalling pathways engaged by ligandbound IGF-IR depend on the number of activated IGFIRs, availability of intracellular signal transducers, the action of negative regulators, and are influenced by extracellular modulators such as the IGFBPs. Although IGF-IR is expressed by all tissues, most reports indicate that IGF-IR levels are upregulated in cancers compared with adjacent non-malignant tissue.

The mechanisms by which IGF-I elicits its effects and how IGF-IR and IR initiate intracellular signalling differs involve the actions of several proteins interacting preferentially with either receptor (23). Furthermore, hybrid receptors that contain one each of the IR and IGF-IR- $\alpha$ and $-\beta$ subunits have been identified. Both hormone binding and signalling properties of the hybrid receptor appear to be different from those of either IR or IGF-IR and they may play a major role in mediating the IGF-I signal in breast cancer (24). The IR-related receptor (IRR) is another receptor with extensive sequence similarity to that of the IGF-IR (25) and as it can associate with the IR it may well also do so with the IGF-IR. On its own, IRR does not bind IGF-I (26), but since IGF-I can bind efficiently to either IGF-IR- $\alpha$ subunit, a hybrid IGF-IR/IRR molecule could be expected to bind IGF-I and display altered signalling specificity.

Clearly, hybrid receptors expand the possible repertoire of cellular responses to hormonal stimulation, and pathology in one receptor could affect both the hybrid and the other receptor, or perhaps be partially compensated for by a hybrid receptor. It is likely that such hybrids also exist in other tissues and could again indicate possible co-operation with IGF-IR in mitogenic signal transduction, facilitating the development and maintenance of the malignant phenotype.

The question of how cells distinguish between IGF-I and IGF-II binding to the IGF-IR also remains unanswered. It is likely that the interaction of IGF-I and IGF-II with their binding proteins direct their overall biological activities. Clearly, in vivo IGF-IR may be activated by different ligands and this activation occurs contemporaneously with signalling from multiple receptors. This results in the activation of similar signalling networks involving multiple interacting components, many of which are, in addition, promiscuous intermediates for multiple hormone, growth factor and cytokine receptors. It remains to be understood how such signalling is integrated and is able to confer specificity. The ultimate impact on cell function depends on the patterns of interaction within these networks, their kinetics and sub-cellular compartmentalisation.

\section{Targets of the GH/IGF-I axis}

\section{Wnt}

The Wnt signalling pathway regulates cell proliferation in adult tissues and its proper regulation is critical for a highly proliferative tissue such as the colonic epithelium. Deregulation of this pathway, either through the inactivation of the adenomatous polyposis coli tumour suppressor gene or an activation mutation of $\beta$-catenin, is the first, virtually obligatory step, on the pathway leading to colorectal neoplasia. IGF-I signalling results in the inactivation of glycogen synthase kinase- $3 \beta$, a key negative regulator of the pathway, which mediates the downregulation of cytoplasmic $\beta$ catenin via the ubiquitin-proteasome pathway. It also leads to the rapid phosphorylation of $\beta$-catenin, its dissociation from E-cadherin, nuclear accumulation and significantly increased transcription from T-cell factor (Tcf)-4 responsive promoters (27). IGF-I-dependent stimulation of the $\beta$-catenin pathway also involves activation of the Ras signalling pathway (28). Hence, IGF-I regulates the two events that are required for modulation of the $\beta$-catenin/Tcf-mediated transcription: the loss of E-cadherin function and the activation of the Wnt-signalling cascade. This suggests that IGF-I acts early in the colonic adenoma-carcinoma progression sequence. However, a late function is not excluded as another function of IGF-I is the promotion of colonic cell migration through reorganisation of integrin receptors and through modulation of E-cadherin/catenin complex function (25).

\section{Angiogenesis}

Tumour growth above a certain size depends on the recruitment of a new vasculature and tumours express a number of autocrine and paracrine factors that activate or otherwise facilitate this process. Vascular endothelial growth factor (VEGF) is the main proangiogenesis factor responsible for neo-vascularisation of many tumours, and signalling through the IGF-IR can increase its expression at the level of transcription, mRNA stability as well as at the protein level (29). A recent report has shown that it effects this through the MAPK pathway activating hypoxia-inducible factor-1 (30). The biological relevance of this is 
revealed by the finding that the increase in VEGF levels is accompanied by an increase in microvessel density (11). Administration of IGF-I to animals is also associated with an increased metastatic potential of tumours that is also accompanied by increased VEGF expression (31).

\section{Apoptosis}

Tumour cells are believed to contain a block in differentiation that renders them more susceptible than normal cells to the induction of apoptosis. Therefore, mutations that inhibit apoptosis and promote survival through pathways such as IGF-IR are actively selected in tumour cells. Expression of the anti-apoptotic Bcl-xL protein is upregulated by IGF-I (32). In addition, IGFI-activated Akt phosphorylates pro-caspase-9, preventing its proteolytic cleavage to active caspase-9. It also binds to caspase- 9 itself, rendering it unable to cleave caspase- 3 and thus preventing progression of the caspase cascade to apoptosis.

\section{IGF-I and oestrogen signalling cross-talk}

Considerable evidence suggests that the GH/IGF-I axis and ER signalling act through a complex cross-talk mechanism to stimulate the proliferation of normal mammary epithelium to increase the risk of breast cancer (33). The oestrogen antagonist tamoxifen blocks IGF-I-mediated proliferation of breast cancer cells in vitro (34) and suppresses serum IGF-I levels in vivo (35). This latter effect is due to several actions. Suppression of pituitary GH secretion occurs first, in part, by enhancing somatostatin actions (36), and second by a direct inhibitory influence on IGF-I expression (37). Tamoxifen also inhibits IGF-I gene expression in common secondary sites for breast cancer metastasis $(37,38)$ and inhibits IGF-IR signal transduction by enhancing tyrosine phosphatase activity. Oestradiol markedly increases GH-mediated expression of IGF-I mRNA in normal mammary tissue, as well as upregulating expression and activation of the IGF-IR in ER-positive breast cancer cells (39). This latter effect enhances activation of downstream signalling components including IRS-1, phosphorylation of which is enhanced by oestrogen. Oestrogen also acts at several other points in the IGF-I signal transduction pathways. It activates several components of the MAPK pathway (40), as well as acting synergistically with IGF-I to increase Akt protein expression and activity (41). At the same time, there is also a reciprocal relationship as IGF-I can directly affect oestrogen metabolism and regulate ER and ERmediated expression in an oestrogen-independent manner $(42,43)$.

Both oestradiol and IGF-I enhance expression of some of the same genes in breast cancer cells including c-fos, myc, early growth response-1, and several genes involved in cell cycle progression (44). Jun and Fos members of the activator protein (AP)-1 transcription complex are regulated by MAPKs and activation of AP-1 has been shown to mediate the growth factorinduced proliferation of breast cancer cells (45). The ER is able to co-activate genes with AP-1, independent of its DNA-binding activity, as well as enhancing IGF-Imediated AP-1 activity (46). This close interaction is reflected at a functional level, with a pronounced synergistic effect of oestrogen and IGF-I on proliferation of breast cancer cell lines, an effect blocked by antibodies against IGF-I (47). Activation of both the MAPK and PI-3K pathways in breast cells by IGF-I has been demonstrated, responses that are blocked by anti-oestrogens (48).

Maintenance of ER expression and its retention of DNA binding are often observed in acquired tamoxifen-resistant tumours (49) and it has been suggested that this may be due to IGF-I-mediated signal transduction pathways and its cross-talk with those of the ER. Indeed, tamoxifen may stimulate cell proliferation by sensitising cells to the proliferative effects of IGF-I. In vitro resistance is accompanied by increased IGF-I binding to breast cells (50) and IGF-IR overexpression reduces oestrogen growth requirements (34). In addition, increased DNA binding by AP-1 occurs in ER-positive MCF-7 cells resistant to tamoxifen as well as in breast tumours from patients resistant to tamoxifen (51). Kinase-dependent phosphorylation of $\mathrm{Ser}^{118}$ or $\operatorname{Ser}^{167}$ of the AF1 domain of the ER $\alpha$ in the absence of oestrogen has been reported (52), and IGF-I induces ligand-independent ER $\alpha$ activation via phosphorylation of $\operatorname{Ser}^{118}$ and $\operatorname{Ser}^{167}$ (53). These effects are via the MAPK pathway and are not observed with either transforming growth factor- $\beta$ or EGF.

\section{Clinical benefits}

This review has discussed the considerable evidence in support of an important role for the GH/IGF-I axis in the development and growth of many cancers. Further knowledge of the mechanisms regulating this influence and the downstream signalling pathways by which these components exert their effects may have important clinical applications. For instance, confirmation of the link between the prospective development of cancer and circulating IGF-I levels may allow the identification of individuals at increased risk to be identified. Next, more vigilant screening procedures could be put in place and manoeuvres taken to reduce IGF-I levels.

Confirmation of this link also raises long-term safety issues regarding the use of recombinant human GH, not only in patients with pituitary $\mathrm{GH}$ deficiency but also to adults (especially elderly) with normal GH secretion, as a supposed tonic and 'elixir of youth'. 
Therapeutic implications lie not only in possible chemoprevention but also in chemotherapy. To date, the most potent therapy for reducing serum IGF-I levels is Pegvisomant, the GHR antagonist (Pfizer, Sandwich, Kent, UK) (54). The potential role of this compound in the treatment of IGF-I-influenced cancers is intriguing. In animal models of metastatic colon cancer, Pegvisomant, in combination with conventional chemotherapy, virtually abolishes metastatic disease (55). It has also been reported to exert inhibitory effects against breast cancer cell lines implanted into athymic mice (56). Whether this can be translated to the treatment of human breast cancer remains to be seen, as does its role in tamoxifen resistance. Further advances in this field are also likely to come from the development of tyrosine kinase inhibitors selective to the IGF-IR.

\section{Conclusions}

In vivo, signalling pathways initiated by IGF-IR activation are extremely complex: several ligands bind to the IGF-IR, which itself can heterodimerise with at least two other receptors but, perhaps most importantly, activation occurs contemporaneously with signalling from numerous other hormone and cytokine receptors. Therefore, signals are transduced along networks that involve multiple interacting components, many of which are shared and are intermediates for numerous hormone, growth factor and cytokine receptors. The pattern of the interactions within these networks, their kinetics and their subcellular compartmentalisation result in alterations to cellular behaviour that increase the risk of deregulated cell growth and, ultimately, permit the growth of neoplastic cells that are more likely to develop into carcinomas in the presence of high IGF-I levels. The contribution of the GH/IGF-I axis to the increased cancer risk and the contribution of this axis to the key regulatory signalling pathways remains a challenge for the future.

\section{References}

1 Ma J, Pollak M, Giovannucci E, Chan JM, Tao Y, Hennekens CH \& Stampfer MJ. Prospective study of colorectal cancer risk in men and plasma levels of insulin like growth factor (IGF)-1 and IGFbinding protein-3. Journal of the National Cancer Institute 1999 $91620-625$.

2 Manousos O, Souglakos J, Bosetti C, Tzonou A, Chatzidakis V, Trichopoulos D, Adami HO \& Mantzoros C. IGF-I and IGF-II in relation to colorectal cancer. International Journal of Cancer 1999 83 15-17.

3 Giovannucci E. Insulin-like growth factor-I and binding protein-3 and risk of cancer. Hormone Research 199951 (Suppl 3) 34-41.

4 Hankinson SE, Willett WC, Colditz GA, Hunter DJ, Michaud DS, Deroo B, Rosner B, Speizer FE \& Pollak M. Circulating concentrations of insulin-like growth factor-I and risk of breast cancer. Lancet 1998351 1393-1396.

5 el Atiq F, Garrouste F, Remacle-Bonnet M, Sastre B \& Pommier G. Alterations in serum levels of insulin-like growth factors and insulin-like growth-factor-binding proteins in patients with colorectal cancer. International Journal of Cancer 199457 491-497.

6 Jenkins PJ \& Besser M. Clinical perspective: acromegaly and cancer: a problem. Journal of Clinical Endocrinology and Metabolism $2001862935-2941$.

7 Jenkins PJ, Frajese V, Jones A-M, Camacho-Hubner C, Lowe DG, Fairclough PD, Chew SL, Grossman AB, Monson JP \& Besser GM. IGF-I and the development of colorectal neoplasia in acromegaly. Journal of Clinical Endocrinology and Metabolism 200085 3218-3221.

8 Cats A, Dullaart RP, Kleibeuker JH, Kuipers F, Sluiter WJ, Hardonk MJ \& de Vries EG. Increased epithelial cell proliferation in the colon of patients with acromegaly. Cancer Research $1996 \mathbf{5 6}$ $523-526$.

9 Hussaini SH, Pereira SP, Veysey MJ, Kennedy C, Jenkins P, Murphy GM, Wass JA \& Dowling RH. Roles of gall bladder emptying and intestinal transit in the pathogenesis of octreotide induced gall bladder stones. Gut 199638 775-783.

10 Le Roith D, Bondy C, Yakar S, Liu JL \& Butler A. The somatomedin hypothesis: 2001. Endocrine Reviews 200122 53-74.

11 Bustin SA, Dorudi S, Phillips SM, Feakins RM \& Jenkins PJ. Local expression of insulin-like growth factor-I affects angiogenesis in colorectal cancer. Tumour Biology 200223 130-138.

12 Kao PC, Matheny AP Jr \& Lang CA. Insulin-like growth factor-I comparisons in healthy twin children. Journal of Clinical Endocrinology and Metabolism $1994 \mathbf{7 8} 310-312$.

13 Giovannucci E, Haiman CA, Platz EA, Hankinson SE, Pollak MN \& Hunter DJ. Dinucleotide repeat in the insulin-like growth factor-I gene is not related to risk of colorectal adenoma. Cancer Epidemiology Biomarkers Prevention 200211 1509-1510.

14 Tajinda K, Carroll J \& Roberts CT. Regulation of insulin-like growth factor I receptor promoter activity by wild-type and mutant versions of the WT1 tumor suppressor. Endocrinology $19991404713-4724$

15 Werner H, Karnieli E, Rauscher FJ \& LeRoith D. Wild-type and mutant p53 differentially regulate transcription of the insulinlike growth factor I receptor gene. PNAS 1996938318 -8323.

16 Idelman G, Glaser T, Roberts CT Jr \& Werner H. WT1-p53 interactions in insulin-like growth factor-I receptor gene regulation. Journal of Biological Chemistry 2003278 3474-3482.

17 Silberstein GB, Van Horn K, Strickland P, Roberts CT Jr \& Daniel CW. Altered expression of the WT1 wilms tumor suppressor gene in human breast cancer. PNAS 199794 8132-8137.

18 Oji Y, Yamamoto H, Nomura M, Nakano Y, Ikeba A, Nakatsuka S, Abeno S, Kiyotoh E, Jomgeow T, Sekimoto M, Nezu R, Yoshikawa Y, Inoue Y, Hosen N, Kawakami M, Tsuboi A, Oka Y, Ogawa H, Souda S, Aozasa K, Monden M \& Sugiyama H. Overexpression of the Wilms' tumor gene WT1 in colorectal adenocarcinoma. Cancer Science $200394712-717$.

19 Hiltunen MO, Koistinaho J, Alhonen L, Myohanen S, Marin S, Kosma VM, Paakkonen M \& Janne J. Hypermethylation of the WT1 and calcitonin gene promoter regions at chromosome 11p in human colorectal cancer. British Journal of Cancer $1997 \mathbf{7 6}$ $1124-1130$

20 Remacle-Bonnet MM, Garrouste FL, Heller S, Andre F, Marvaldi JL \& Pommier GJ. Insulin-like growth factor-I protects colon cancer cells from death factor-induced apoptosis by potentiating tumor necrosis factor alpha-induced mitogen-activated protein kinase and nuclear factor kappaB signaling pathways. Cancer Research $2000602007-2017$.

21 Kulik G \& Weber MJ. Akt-dependent and -independent survival signaling pathways utilized by insulin-like growth factor I. Molecular and Cellular Biology 199818 6711-6718.

22 Burtscher I, Compagni A, Lamm GM \& Christofori G. An insulinlike growth factor-mediated, phosphatidylinositol 3' kinase-independent survival signaling pathway in beta tumor cells. Cancer Research $1999593923-3926$.

23 Laviola L, Giorgino F, Chow JC, Baquero JA, Hansen H, Ooi J, Zhu J, Riedel H \& Smith RJ. The adapter protein Grb10 associates preferentially with the insulin receptor as compared with the IGF-I 
receptor in mouse fibroblasts. Journal of Clinical Investigation 1997 $99830-837$.

24 Pandini G, Vigneri R, Costantino A, Frasca F, Ippolito A, FujitaYamaguchi Y, Siddle K, Goldfine ID \& Belfiore A. Insulin and insulin-like growth factor-I (IGF-I) receptor overexpression in breast cancers leads to insulin/IGF-I hybrid receptor overexpression: evidence for a second mechanism of IGF-I signaling. Clinical Cancer Research 19995 1935-1944.

25 Shier P \& Watt VM. Primary structure of a putative receptor for a ligand of the insulin family. Journal of Biological Chemistry 1989 264 14605-14608.

26 Zhang B \& Roth RA. Binding properties of chimeric insulin receptors containing the cysteine-rich domain of either the insulin-like growth factor I receptor or the insulin receptor related receptor. Biochemistry 199130 5113-5117.

27 Playford MP, Bicknell D, Bodmer WF \& Macaulay VM. Insulin-like growth factor 1 regulates the location, stability, and transcriptional activity of beta-catenin. PNAS 200097 12103-12108.

28 Desbois-Mouthon C, Cadoret A, Blivet-Van Eggelpoel MJ, Bertrand F, Cherqui G, Perret C \& Capeau J. Insulin and IGF-1 stimulate the beta-catenin pathway through two signalling cascades involving GSK-3beta inhibition and Ras activation. Oncogene 200120 $252-259$.

29 Akagi Y, Liu W, Zebrowski B, Xie K \& Ellis LM. Regulation of vascular endothelial growth factor expression in human colon cancer by insulin-like growth factor-I. Cancer Research $1998 \mathbf{5 8}$ 4008-4014.

30 Fukuda R, Hirota K, Fan F, Jung YD, Ellis LM \& Semenza GL. Insulin-like growth factor 1 induces hypoxia-inducible factor 1mediated vascular endothelial growth factor expression, which is dependent on MAP kinase and phosphatidylinositol 3-kinase signaling in colon cancer cells. Journal of Biological Chemistry $200227738205-38211$.

31 Wu Y, Yakar S, Zhao L, Hennighausen L \& LeRoith D. Circulating insulin-like growth factor-I levels regulate colon cancer growth and metastasis. Cancer Research 200262 1030-1035.

32 Parrizas M \& LeRoith D. Insulin-like growth factor-1 inhibition of apoptosis is associated with increased expression of the bcl-xL gene product. Endocrinology 1997138 1355-1358.

33 Laban C, Bustin SA \& Jenkins PJ. The GH-IGF-I axis and breast cancer. Trends in Endocrinology and Metabolism 200214 28-34.

34 Guvakova MA \& Surmacz E. Tamoxifen interferes with the insulin-like growth factor I receptor (IGF-IR) signaling pathway in breast cancer cells. Cancer Research 199757 2606-2610.

35 Bonanni B, Johansson H, Gandini S, Guerrieri-Gonzaga A, Torrisi R, Sandri MT, Cazzaniga M, Mora S, Robertson C, Lien EA \& Decensi A. Effect of low dose tamoxifen on the insulin-like growth factor system in healthy women. Breast Cancer Research and Treatment $20016921-27$.

36 Tannenbaum GS, Gurd W, Lapointe M \& Pollak M. Tamoxifen attenuates pulsatile growth hormone secretion: mediation in part by somatostatin. Endocrinology 1992130 3395-3401.

37 Huynh HT, Tetenes E, Wallace L \& Pollak M. In vivo inhibition of insulin-like growth factor I gene expression by tamoxifen. Cancer Research 199353 1727-1730.

38 Huynh H \& Pollak M. Enhancement of tamoxifen-induced suppression of insulin-like growth factor I gene expression and serum level by a somatostatin analogue. Biochemical and Biophysical Research Communications 1994203 253-259.

39 Stewart AJ, Johnson MD, May FE \& Westley BR. Role of insulinlike growth factors and the type I insulin-like growth factor receptor in the estrogen-stimulated proliferation of human breast cancer cells. Journal of Biological Chemistry $1990 \mathbf{2 6 5}$ 21172-21178.

40 Migliaccio A, Di Domenico M, Castoria G, De Falco A, Bontempo $\mathrm{P}$, Nola E \& Auricchio F. Tyrosine kinase/p21ras/MAP-kinase pathway activation by estradiol-receptor complex in MCF-7 cells. EMBO Journal $1996 \mathbf{1 5} 1292-1300$.
41 Ahmad S, Singh N \& Glazer RI. Role of AKT1 in 17beta-estradioland insulin-like growth factor I (IGF-I)-dependent proliferation and prevention of apoptosis in MCF-7 breast carcinoma cells. Biochemical Pharmacology 199958 425-430.

42 Lee AV, Weng CN, Jackson JG \& Yee D. Activation of estrogen receptor-mediated gene transcription by IGF-I in human breast cancer cells. Journal of Endocrinology 1997152 39-47.

43 Stoica A, Saceda M, Fakhro A, Joyner M \& Martin MB. Role of insulin-like growth factor-I in regulating estrogen receptoralpha gene expression. Journal of Cellular Biochemistry $2000 \mathbf{7 6}$ 605-614.

44 Johnston SR, Head J, Pancholi S, Detre S, Martin LA, Smith IE \& Dowsett M. Integration of signal transduction inhibitors with endocrine therapy: an approach to overcoming hormone resistance in breast cancer. Clinical Cancer Research 20039 $524 S-532 S$.

45 Chen TK, Smith LM, Gebhardt DK, Birrer MJ \& Brown PH. Activation and inhibition of the AP-1 complex in human breast cancer cells. Molecular Carcinogenesis 199615 215-226.

46 Philips A, Chalbos D \& Rochefort H. Estradiol increases and antiestrogens antagonize the growth factor-induced activator protein1 activity in MCF7 breast cancer cells without affecting c-fos and c-jun synthesis. Journal of Biological Chemistry $1993 \mathbf{2 6 8}$ 14103-14108.

47 Freiss G, Prebois C, Rochefort H \& Vignon F. Anti-steroidal and anti-growth factor activities of anti-estrogens. Journal of Steroid Biochemistry and Molecular Biology 199037 777-781.

48 Freiss G, Puech C \& Vignon F. Extinction of insulin-like growth factor-I mitogenic signaling by antiestrogen-stimulated Fasassociated protein tyrosine phosphatase-1 in human breast cancer cells. Molecular Endocrinology 199812 568-579.

49 Johnston SR, Lu B, Dowsett M, Liang X, Kaufmann M, Scott GK, Osborne CK \& Benz CC. Comparison of estrogen receptor DNA binding in untreated and acquired antiestrogen-resistant human breast tumors. Cancer Research 199757 3723-3727.

50 Wiseman LR, Johnson MD, Wakeling AE, Lykkesfeldt AE, May FE \& Westley BR. Type I IGF receptor and acquired tamoxifen resistance in oestrogen-responsive human breast cancer cells. European Journal of Cancer 1993 29A 2256-2264.

51 Johnston SR, Lu B, Scott GK, Kushner PJ, Smith IE, Dowsett M \& Benz CC. Increased activator protein-1 DNA binding and c-Jun NH2-terminal kinase activity in human breast tumors with acquired tamoxifen resistance. Clinical Cancer Research 19995 251-256.

52 Joel PB, Smith J, Sturgill TW, Fisher TL, Blenis J \& Lannigan DA. pp90rsk1 regulates estrogen receptor-mediated transcription through phosphorylation of Ser-167. Molecular and Cellular Biology 199818 1978-1984.

53 Aronica SM \& Katzenellenbogen BS. Stimulation of estrogen receptor-mediated transcription and alteration in the phosphorylation state of the rat uterine estrogen receptor by estrogen, cyclic adenosine monophosphate, and insulin-like growth factor-I. Molecular Endocrinology 19937 743-752.

54 Kopchick JJ, Parkinson C, Stevens EC \& Trainer PJ. Growth hormone receptor antagonists: discovery, development, and use in patients with acromegaly. Endocrine Reviews 200223 623-646.

55 Maple S, Fernandes J, Khandwala H, Scarlett JA, Davis RA, Flyvbjerg A, McCutcheon IE \& Friend KE. Pegvisomant inhibits tumor growth in a syngenic model of colon cancer metastasis. Proceedings of the 83rd American Endocrine Society, Denver, USA 2001 P1218.

56 Friend KE. Cancer and the potential place for growth hormone receptor antagonist therapy. Growth Hormone and IGF Research 200111 (Suppl A) S121-S123.

Received 17 March 2004

Accepted 19 April 2004 